\title{
Self expanding stents for the management of aorto-ostial stenoses in saphenous vein bypass grafts
}

Jan-Eric Nordrehaug, Kim A Priestley, Nicolas A F Chronos, Anthony F Rickards, Nigel P Buller, Ulrich Sigwart

\begin{abstract}
Objective-To assess the early and follow up results of implantation of a self expanding stent in aorto-ostial stenoses of vein grafts.

Design-Prospective, non-randomised, observational study.

Setting-Tertiary referral centre for cardiac diseases.

Patients-Nineteen patients with ostial stenoses of saphenous vein grafts.

Main outcome measures and resultsStents were successfully deployed in all 19 patients with satisfactory angiographic results. In one patient this required two attempts. There were no deaths and no major procedural complications related to ostial stenting. Before discharge two (11\%) patients had thrombosis of the ostial stent; one patient had a $Q$ wave myocardial infarction. Femoral artery bleeding occurred in three (16\%) patients. Angiographic follow up was performed in 18 patients at a mean of seven months. Restenosis within the ostial stent was detected in three $(16 \%)$ patients. Twelve $(63 \%)$ patients had an improved functional status at a mean follow up of nine months. One patient died suddenly at three months. Three (16\%) patients required additional revascularisation procedures because of symptoms caused by restenosis within the ostial stent during follow up.

Conclusions-Intracoronary stenting is an attractive treatment for the management of patients with vein graft ostial stenoses.
\end{abstract}

Department of Invasive Cardiology, Royal Brompton National Heart and Lung Hospital, Sydney Street, London J-E Nordrehaug K A Priestley N A F Chronos A F Rickards N P Buller U Sigwart

Correspondence to: Dr U Sigwart, Departmen of Invasive Cardiology, Royal Brompton Hospital, Sydney Street, London SW3 6NP.

Accepted for publication 21 March 1994.

\section{(Br Heart f 1994;72:285-287)}

Conventional balloon angioplasty of aortoostial lesions often produces a suboptimal procedural complications and restenosis than angioplasty of non-ostial lesions. Indeed, in the major multicentre trial in the USA, balloon angioplasty for right coronary artery ostial stenosis was unsuccessful in $11(21 \%)$ of 53 patients, of whom five $(9 \%)$ required emergency coronary artery bypass grafting because of abrupt closure. ${ }^{1}$ Angina subsequently recurred in $20(48 \%)$ of the 42 angiographic result and has a higher risk of patients with an initially successful outcome after a mean follow up of 12.5 months. Sixteen (38\%) of these 42 patients had repeat angiography which confirmed restenosis. Balloon angioplasty of ostial lesions in saphenous vein grafts has an even higher restenosis rate; $79 \%$ in one series. ${ }^{2}$ In view of these poor results several alternatives or adjuncts to conventional angioplasty have been investigated for the treatment of aorto-ostial lesions. Directional coronary atherectomy ${ }^{34}$ and excimer laser angioplasty ${ }^{5}$ are reported to have a higher primary success rate than balloon angioplasty, but the restenosis rates are similar. We report the initial and follow up results of the implantation of a self expanding stent in patients with aorto-ostial stenoses in bypass grafts.

\section{Patients and methods}

Nineteen patients were implanted with a self expanding stent (Wallstent, Medinvent SA, Lausanne, Switzerland) in the ostium of a saphenous vein graft. Table 1 summarises the clinical characteristics of the patients. All patients had a significant stenosis ( $\geqslant 70 \%$ ) within $3 \mathrm{~mm}$ of the ostium of the graft. The mean diameter of the stenosis was $87(7) \%$ before intervention, as assessed by caliper measurements in standard orthogonal views. The vein graft supplied the left anterior descending artery in seven patients, the circumflex artery in six, and the right coronary artery in six. The target lesion was a restenosis in five $(26 \%)$ patients.

\section{PROCEDURE}

All patients gave informed consent to stent insertion and a standard procedure for implantation of the self expanding stent was followed. The ostial lesion was predilated

Table 1 Clinical characteristics of patients

\begin{tabular}{ll}
\hline Characteristic & \\
\hline Age (mean (SD)) & $60(9) \mathrm{yr}$ \\
Sex ratio (male:female) & $15 \cdot 4$ \\
Angina (NYHA): & 2 \\
Grade 2 & 11 \\
Grade 3 & 6 \\
Grade 4 & $11(58 \%)$ \\
Previous myocardial infarction & $57(12) \%$ \\
Ejection fraction (mean (SD) )
\end{tabular}

NYHA, New York Heart Association. 
using an angioplasty balloon catheter and the special stent delivery system ${ }^{6}$ advanced over the angioplasty guide wire via an $8 \mathrm{Fr}$ guide catheter. Correct positioning of the stent was facilitated by markers at its proximal and distal ends. The constraining membrane was partially retracted to allow expansion of the distal end of the stent, thus anchoring the stent in position. The guide catheter was pulled back into the aorta and the stent allowed to expand fully by manipulation of the delivery catheter. Further balloon inflations within the stent were often required to obtain a satisfactory angiographic result.

Sixteen (84\%) patients had additional interventions at the same procedure. Conventional balloon angioplasty of a second lesion was performed in $12(63 \%)$ patients, one patient had two adjacent stents, and three patients had a second stent in another location.

\section{ANTI-THROMBOTIC DRUG REGIMEN}

Aspirin (150-300 mg) was started the day before the procedure and continued indefinitely. Warfarin and dipyridamole were started at the same time and continued for three months. Dextran 40 was given intravenously during the procedure and continued over the next three to five hours $(500 \mathrm{ml}$ total). Intra-arterial heparin (15 $000 \mathrm{IU})$ was administered at the start of the procedure with additional boluses each hour to keep the activated clotting time greater than $300 \mathrm{sec}-$ onds. Heparin was continued on the ward until effective anticoagulation with warfarin was established (international normalised ratio $2 \cdot 5-3 \cdot 5)$.

\section{STATISTICAL ANALYSIS}

Values are expressed as mean (standard deviation (SD)).

\section{Results}

EARLY RESULTS

A stent was successfully deployed in the ostial lesion in all 19 patients. The mean diameter stenosis was 51 (20)\% after balloon predilation and this was reduced by stent implantation to less than $20 \%$ in all patients. In one patient the initial stent could not be accurately deployed. It was retracted back into the aorta and subsequently deployed in the right iliac artery without any adverse effects. A second stent was successfully placed in the ostial lesion. The mean unconstrained stent diameter used was $4.9(1.0) \mathrm{mm}$ (range $3 \cdot 0-6 \cdot 0$ ) and the stent length was 27 (5) $\mathrm{mm}$ (range 15-40).

Table 2 gives procedural and in-hospital complications related to the ostial stent. In addition, one patient had thrombosis of a second stent placed in a non-ostial location. This patient had a $Q$ wave myocardial infarction despite intracoronary thrombolysis and repeat angioplasty. A second patient had a non- $Q$ wave myocardial infarction after abrupt closure of a balloon angioplasty site. The vessel was reopened and a stent implanted with an excellent angiographic result.
Table 2 Procedural and in-hospital complications related to the ostial stent

\begin{tabular}{ll}
\hline Complication & No (\%) \\
\hline Death & 0 \\
Emergency coronary operation & 0 \\
Myocardial infarction & $1(5)$ (non-Q wave) \\
Stent thrombosis & $2(11)^{\star}$ \\
Femoral artery bleeding & $3(16)^{\star}$ \\
\hline
\end{tabular}

^One patient had a $Q$ wave myocardial infarction.

Table 3 Angiographic follow up $(n=18)$

\begin{tabular}{lc}
\hline- & $n(\%)$ \\
\hline Patent ostial stent & $15(83)$ \\
Restenosis within ostial stent & $3(17)$ \\
Restenosis elsewhere & $3(17)^{\star}$ \\
New lesions & $3(17)^{\star}$
\end{tabular}

*Three of 12 patients treated by balloon angioplasty (restenosis rate $25 \%$ ).

Table 4 Clinical follow up

\begin{tabular}{ll}
\hline Functional state & No of patients (\%) \\
\hline Angina improved after intervention: & $12(63)$ \\
-Free of symptoms & 10 \\
-Residual angina improved $\geqslant 1$ & 2 \\
NYHA class & $6(32)$ \\
Recurrent angina & 0 \\
Myocardial infarction & $1(5)$ \\
Death &
\end{tabular}

NYHA, New York Heart Association

Three (16\%) patients had femoral artery bleeding; all three required an operation for repair.

FOLLOW UP

Follow up angiograms were obtained in all 18 eligible patients ( $95 \%$ angiographic follow up); one patient died before the planned follow up angiography. Angiography was performed early in one patient because of symptoms (four months). In the remaining patients angiography was performed after a mean of seven months (range 5-18 months). Table 3 gives the results. Restenosis within the ostial stent, defined as $\geqslant 50 \%$ diameter reduction, was detected in three $(17 \%)$ patients.

The mean clinical follow up was nine (three) months; the results are shown in table 4. Twelve $(63 \%)$ patients had an improved functional status at follow up; indeed, 10 (53\%) patients were asymptomatic. One patient died suddenly at three months. He had had a thrombosis of a non-ostial stent, resulting in a $Q$ wave myocardial infarction, while in hospital. Necropsy results were not available.

Three (16\%) patients required repeat angioplasty because of symptoms due to restenosis within the ostial stent during follow up. A further four patients required additional revascularisation procedures because of restenosis after balloon angioplasty at a second site, or because of new disease.

\section{Discussion}

The results of conventional balloon angioplasty of aorto-ostial lesions are often disappointing. Typically, the lesions are difficult to dilate and require high pressure inflations. In a series of 53 patients with right 
coronary ostial stenoses the mean diameter stenosis was 33.5 (26)\% after balloon angioplasty and procedural success was achieved in $79 \%$ of patients. ${ }^{1}$ In comparison, laser angioplasty of ostial stenoses has a reported procedural success of $96 \%$ and directional coronary atherectomy of between $78 \%$ and $86 \% .{ }^{34}$ In our series of 19 patients with ostial lesions in vein grafts the mean diameter stenosis after balloon predilation was 51 (20)\%. The implantation of a stent produced an excellent angiographic result in all patients, although one patient required a second attempt. Stent deployment in the ostium of vein grafts thus has a similar level of success to stent deployment in other locations in native coronary arteries and bypass grafts. ${ }^{7-9}$

The flexibility of the self expanding stent and the availability of a variety of lengths make it particularly well suited for use in aorto-ostial lesions and vein grafts. Its precise positioning in the ostial location, however, requires considerable expertise. The self expanding feature implies that significant shortening of the stent occurs on delivery. As the distal portion of the stent is deployed first the proximal end will move into the target vessel until an equilibrium is reached between radial expansion and lesion compliance. This factor must be considered when positioning the distal end of the stent. If incorrectly positioned the proximal end of the stent may protrude into the aorta or not cover the lesion completely. Protrusion of the stent into the aorta could theoretically provide a nidus for thrombus formation. This has not been realised in clinical practice. None of our patients had any overt thromboembolic phenomenon.

Procedural complications are high after balloon dilation of aorto-ostial lesions, with up to $10 \%$ of patients needing an emergency coronary operation. ${ }^{1}$ An emergency operation was required in between $0 \%$ and $4.9 \%$ of patients with ostial lesions after directional atherectomy $\mathrm{y}^{34}$ and in $2.6 \%$ after excimer laser angioplasty. ${ }^{5}$ There was no major procedural complication in our patients. Thrombosis of the ostial stent, however, occurred in two ( $11 \%)$ patients. In one patient stent thrombosis occurred after premature discontinuation of anticoagulation drugs, but in the other patient the strict anticoagulation regimen was adhered to. In the two patients the stent was disobliterated by intracoronary thrombolytics and repeat angioplasty; one patient sustained a $\mathbf{Q}$ wave myocardial infarction. Stent thrombosis is a concern and published studies suggest that the self expanding stent ${ }^{10-12}$ may have a higher thrombotic tendency than other stent designs. ${ }^{8}$

The incidence of bleeding complications is similar in all stent studies and relates to the intensive anticoagulation and regimen required. It is hoped that femoral bleeding, which occurred in $16 \%$ of patients in our series, will be reduced by new devices and techniques for securing femoral haemostasis. ${ }^{13} 14$

A $17 \%$ restenosis rate is lower than that reported for aorto-ostial lesions treated by conventional balloon angioplasty $(48-79 \%),{ }^{12}$ directional atherectomy (14-60\%), ${ }^{34}$ or laser (47\%) angioplasty. ${ }^{5}$ The restenosis rate is particularly low considering that the stents were placed in the ostial location of vein grafts, a site with a particularly high predilection for restenosis after balloon angioplasty $(79 \%) .{ }^{2}$ Several factors may contribute to this low restenosis rate. In particular, lower restenosis rates are associated with de novo lesions ( $74 \%$ in our series), a residual stenosis of $<20 \%$ after stenting (achieved in all our patients), ${ }^{15}$ and large stent diameter (mean $4.9 \mathrm{~mm}$ in our series, smallest $3 \mathrm{~mm}$ ). ${ }^{15}$

In conclusion, the morbidity and mortality associated with a repeat coronary operation make stenting an attractive treatment in patients with vein graft ostial stenoses. In this series the self expanding stent was associated with a high angiographic success rate, low procedural complications, and a low risk of restenosis. Stent thrombosis and femoral artery bleeding were significant problems, but these may be reduced with newer stent designs and devices for securing femoral haemostasis. Randomised studies comparing the results of stenting of aorto-ostial lesions in saphenous vein grafts with those of directional atherectomy and excimer laser are urgently needed.

1 Topol EJ, Ellis SG, Fishman J, et al. Multicenter study of percutaneous transluminal angioplasty for right coronary artery ostial stenosis. f Am Coll Cardiol 1987;9:1214-8.

2 Douglas J, King S, Roubin G, Schlumpf M. Percutaneous angioplasty of venous aortocoronary graft stenoses: late angiographic and clinical outcome [abstract]. Circulation 1986;74(suppl):II-281.

3 Popma JJ, Dick RJL, Haudenschild CC, Topol EJ, Ellis SG. Atherectomy of right coronary ostial stenosis: initial and long-term results, technical features and histologic findings. Am $\mathcal{F}$ Cardiol 1991;67:431-3.

4 Robertson GC, Simpson JB, Vetter JW, et al. Directiona coronary atherectomy for ostial lesions [abstract] Circulation 1991;84(suppl):II-251.

5 Eigler NL, Douglas Jr JS, Margolis JR, Hestrin L, Litrack FI, ELCA Investigators. Excimer laser angioplasty of 1, ELCAtial stenosis: results of the ELCA registry [abstract]. Circulation 1991;84(suppl):II-251.

6 Sigwart U, Puel J, Mirkovitch V, Joffre F, Kappenberger L. Intravascular stents to prevent occlusion and restenosis 1987;316:701-6.

7 Roubin GS, Cannon AD, Agrawal SK, et al. Intracoronary stenting for acute and threatened closure complicating stenting for acute and threatened closure complicating percutaneous transluminal

8 Schatz RA, Baim DS, Leon M, et al. Clinical experience with the Palmaz-Schatz coronary stent. Initial results of a with the Palmaz-Schatz coronary stent. Initial

9 Sigwart U, Urban P, Golf S, et al. Emergency stenting for acute occlusion after coronary balloon angioplasty. Circulation 1988;78:1121-7.

10. Serruys PW, Strauss BH, Beatt KJ, et al. Angiographic follow-up after placement of a self-expanding coronary artery stent. $N$ Engl $\mathcal{F}$ Med 1991;324:13-7.

11 Strauss BH, Serruys PW, Bertrand ME, et al. Quantitative angiographic follow-up of the coronary Wallstent in native vessels and bypass grafts (European experienceMarch 1986 to March 1990. Am F Cardiol 1992;69. 475-81.

12 Goy J, Sigwart U, Vogt P, et al. Long-term follow-up of the first 56 patients treated with intracoronary selfexpanding stents (the Lausanne experience). $A m$ Cardiol 1991;67:569-72.

13 Nordrehaug JE, Chronos N, Gunnes P, Rickards AF, Buller NP, Sigwart U. Safety, efficacy and patient tolerability of a new inflatable femoral artery compression device after cardiac angiography [abstract]. $\mathrm{Br}$ Heart $\mathfrak{f}$ 1992;68:82.

14 Gibbs JSR, Slade AKB, Blake J, et al. Femoral arteria hemostasis using a collagen plug after coronary artery

15 Strauss BH, Serruys PW, de Scheerder IK, et al. Relative risk analysis of angiographic predictors of restenosis risk analysis of angiographic predictors of restenosis
within the coronary Wallstent. Circulation 1991;84: within the 43 . 